\title{
As condições objetivas para o enfrentamento ao COVID-19: abismo social brasileiro, o racismo, e as perspectivas de desenvolvimento social como determinantes \\ Objective conditions for confronting COVID-19: Brazilian social abyss, racism, and social development perspectives as determinants
}

\section{Tricia Viviane Lima Calmon ${ }^{1}$}

\begin{abstract}
RESUMO
O Brasil construiu ao longo da sua história um abismo social amparado na herança da escravidão racial, que tem relegado milhões de pessoas a viverem, atualmente, em extrema situação de pobreza. A necessidade de enfrentamento à COVID-19 expôs ainda mais a realidade do país, na medida em que grande parcela da sua população, que vive em situação de rua e em territórios bastante empobrecidos, tem encontrado dificuldade em realizar as orientações mínimas para prevenção à proliferação do coronavírus, como o isolamento social e higienização adequada. Nesse artigo discutimos as bases dessas dificuldades e a necessidade de alcançarmos um outro patamar de desenvolvimento social que supere a tragédia social produzida pela desigualdade sociorracial e econômica.
\end{abstract}

Palavras chave: extrema pobreza; COVID-19; desigualdade racial; política pública.

\begin{abstract}
Throughout its history, Brazil has built a social abyss based on the legacy of racial slavery, which has relegated millions of people to live in extreme poverty today. The need to confront Covid-19 further exposed the reality of the country, as a large portion of its population, living on the streets and in very impoverished territories, has found it difficult to carry out the minimum guidelines for preventing proliferation coronavirus, such as social isolation and proper hygiene. In this article we discuss the bases of these difficulties and the need to reach another level of social development that overcomes the social tragedy produced by socio-racial and economic inequality.
\end{abstract}

Keywords: Extreme poverty; COVID-19; racial inequality; public policy.

Embora pareça óbvio para alguns, consideramos importante frisar que quando falamos do abismo social brasileiro, não estamos falando apenas dos empobrecidos e como estes "serão salvos", falamos, sobretudo, dos ricos, da classe média e do modelo de sociedade que vislumbramos. A COVID-19 é a atualização da oportunidade de falarmos do passado, do presente e do futuro do nosso país. Não chega a ser uma doença democrática, como afirmam alguns, visto que as condições de prevenção e cuidado se impõem de formas diferentes a segmentos sociais distintos, assim como o potencial de letalidade do vírus. Porém, como os

\footnotetext{
1 Mestranda em Desenvolvimento e Gestão Social (CIAGS/ Faculdade de Administração da UFBA); Especialista em Políticas Públicas de Gênero e Raça (Núcleo de Estudos Interdisciplinares da Mulher / Faculdade de Filosofia e Ciências Humanas da UFBA - 2015). Atualmente, ocupa o cargo de Coordenadora Geral do Programa Corra pro Abraço (Secretaria de Justiça e Direitos Humanos e Desenvolvimento Social do Estado da Bahia). É Conselheira do Conselho Estadual de Políticas de Drogas e do Fundo Baobá para a Equidade Racial. E-mail: triciacalmon@hotmail.com.
}

Artigo Convidado para compor este Fórum Especial em Democracia, Políticas Públicas e COVID-19. Agradecemos à autora a participação neste debate tão urgente. 
ricos e classe média alta foram a porta de entrada do vírus no Brasil, tendo entre esses muitos vitimados, estamos de fato diante de um assunto que, em aspectos gerais, tem interessado a toda sociedade. Aproveitemos o debate.

\section{Sobre o porquê que as classes mais empobrecidas têm dificuldade em cumprir o isolamento social}

A fratura está exposta. Milhões de mulheres, homens e crianças vivem em situação extrema de pobreza no Brasil, à rigor isso significa: milhares de pessoas no subemprego dependem do movimento das ruas para fazer o "corre" e garantir o recurso para sobreviver mais um dia; dessas pessoas, muitas vivem com suas famílias em casas de um cômodo sem absolutamente nenhum conforto, em ocupações de casarões antigos, temendo desabamento ou despejo, ou em vilas onde pagam a morada com o auxílio aluguel de $R \$ 300,00^{2}$ concedido pelas Prefeituras; disputando, por fim, com aqueles que dormem nas ruas, os recursos que circulam de lá - doações de roupas, comida e tarefas pontualmente remuneradas (os chamados "corres").

Para esse conjunto de milhares de pessoas espalhadas pelo Brasil, viver em situação de rua é uma realidade, seja em barracos nos bairros ou nos centros das grandes cidades (onde ficam mais visíveis). Sim, estamos aqui necessariamente ampliando o conceito do que é viver em situação de rua. Ou passamos a enxergar essa realidade como ela é, ou seguiremos no processo de autoengano reproduzindo a ideia de que as pessoas que estão nas ruas "brotam do asfalto", optaram por estar ali ou foram conduzidas para as ruas devido ao uso de drogas. Problemáticas complexas exigem saídas e explicações igualmente complexas.

A pobreza extrema e a falta de amparo social levam as pessoas a viverem nas ruas. Via de regra, a história de vida das pessoas que vivem nas ruas está marcada por eventos / processos de violência: abuso sexual, violência doméstica, homofobia, transfobia, prisão ou morte violenta de parentes, por exemplo. $\mathrm{O}$ uso de drogas muitas vezes decorre das estratégias para sobreviver nas ruas, onde não se pode dormir sem o risco de sofrer agressões ou ter os pertences subtraídos.

O que algumas pessoas chamam de opção deve trazer antes a pergunta: optou pela rua em relação a quê? Uma sociedade punitivista e moralista como a nossa se apressa em responder e se dispõe pouco a ouvir e perguntar. Talvez parta daí o exercício do olhar que pode gerar mudanças.

\section{Sobre o racismo, as perspectivas de desenvolvimento e o abismo sociorracial historicamente construído no Brasil}

O racismo institucional é construído pari passu à constituição do Estado brasileiro, de modo que não é raro atos racistas serem chamados de atos tão somente burocráticos, associando burocracia equivocadamente à ineficiência. No Brasil, quão mais os territórios são habitados por pessoas negras, mais criminalizados e empobrecidos eles são. Ali vai faltar deliberadamente a gestão de políticas públicas para a garantia de direitos sociais e sobrará a vigília armada, a partir da política de segurança pública. Não à toa, as prisões e mortes violentas atingem mais as pessoas negras. A respeito das prisões, por exemplo, é possível ver dados da Defensoria Pública do Estado da Bahia apresentados no Relatório das Audiências de Custódia na Comarca de Salvador (2019):

Com relação a renda, em 2017 e 2018, a maior parte dos flagranteados se concentram na faixa dos que recebem valor abaixo de 2 (dois) salários mínimos, correspondendo a 98,7\% do total de flagrantes analisados, desconsiderando-se o registro "não informado".

Tem-se assim que o perfil social do flagranteado no período global analisado corresponde a um homem $(94,2 \%)$ negro $(98,8 \%)$, jovem $(68,3 \%)$, com ensino fundamental incompleto

\footnotetext{
${ }^{2}$ Em Salvador-Ba o auxílio aluguel equivale a $\mathrm{R} \$ 300,00$, esse valor varia a depender o município.
} 
(54,6\%) e com renda inferior a 2 (dois) salários mínimos (98,7\%). (DPE-BA, 2019, p.88-89)

Os crimes relacionados ao uso e venda de drogas são dos mais destacáveis nos números que levam homens e mulheres à prisão. A maior parte das pessoas presas são negras. O uso e comércio ilegal de drogas, porém não se faz apenas nos territórios habitados por maioria de negros e empobrecidos; ao contrário, no Brasil, as drogas circulam com grande facilidade e segurança nos territórios ocupados majoritariamente por pessoas brancas. O que explicaria, para nós, o julgamento à pessoa e não à conduta, senão o racismo?

A escravidão racial que vigorou formalmente no Brasil até 1888 deixou vivas marcas na estrutura social e vai perseguir a gestão pública que se pretenda justa e democrática até que esse dado da realidade histórica deixe de ser ignorado e seja trazido para o centro das políticas públicas. É necessário imprimir intencionalidade a cada ato, do contrário, o racismo seguirá nos boicotando enquanto sociedade.

O trabalho escravo ergueu riquezas e o racismo, este que é anterior a escravidão racial experimentada no Brasil (MOORE, 2009), naturalizou a condição de riqueza dos brancos e a condição de pobreza dos negros, sendo que isso não é algo fácil de desconstruir. Relações raciais, assim como as relações de classe e de gênero, envolvem relações de poder, e o poder, por natureza não é cedido. Este pode se deslocar a partir de correlação de forças, o que passa pelos conflitos e rupturas, exigindo coragem e uma compreensão cristalina da realidade e dos papeis dos diferentes atores políticos.

Por tudo isso, ao contrário do que pensam muitos, não se trata de algo que se resolve tão somente educando as pessoas, a educação é uma parte da tarefa, é verdade, mas no máximo nos dará polidez e ainda mais condições de realizar intervenções para no final manter as coisas nos mesmos lugares. Não intentamos que após passar por todas as dificuldades e arranjos impostos pelo contexto COVID-19 as coisas retornem para os mesmos lugares, isso porque aquele "normal" não era bom para milhões de brasileiras/os. Essas mesmas pessoas empobrecidas, que novamente são cobradas e acusadas de não colaborarem com o isolamento, quando na realidade não thes foram permitidas as condições.

Ao longo da história do Brasil, o segmento populacional negro esteve posicionado de diferentes formas dialogando com as diversas perspectiva de desenvolvimento. Até 1888, as pessoas negras eram necessárias para rodar a economia dentro do modelo escravagista; após a abolição, a presença negra foi considerada como elemento de atraso para o projeto de nação do país; na década de 1930, Gilberto Freire já apresentava compreensões positivas a respeito da presença negra e indígena e, embora não tenha cunhado o termo, reportam aà ele a ideia do mito da democracia racial no Brasil. Faltou a ele, ao nosso ver, a ele destacar a assimetria de poder impressa na relação entre brancos, negros e indígenas naquela sociedade brasileira; o pós- segunda guerra fortalece a perspectiva do Brasil como um suposto exemplo de harmonia racial. Alguns autores à época, como Florestan Fernandes, denunciaram, a partir do projeto UNESCO, a realidade das desigualdades raciais no Brasil. Já na década de 1990, a produção de dados sobre o perfil populacional brasileiro e os debates promovidos com o protagonismo do movimento negro, torna irrefutável a existência de racismo no país e políticas públicas começam a ser propostas em diversas áreas para promover o seu combate e a igualdade racial.

Assim, o tema do enfrentamento ao racismo e da promoção da igualdade racial entrou de vez na agenda pública brasileira que passa a se movimentar no que Sueli Carneiro chamou de neo-democracia racial, isto porque a maior parte da sociedade já não nega o racismo, mas relativiza os seus efeitos e, sobretudo, questiona a adoção de medidas radicais (necessárias) de enfrentamento ao mesmo.

Para atender a estes dois interesses, a neo-democracia racial estabelece a capacidade de consumo como o limite da cidadania negra. Desse modo, no novo desenho de relações 
raciais que se delineia às portas do novo milênio, o status de consumidor é garantido a alguns afro-descendentes, enquanto, por outro lado, ampliam-se os mecanismos de exclusão social da maioria. (CARNEIRO, 2002, p. 212)

Embora tenhamos observado algum avanço em termos da adoção de políticas públicas de igualdade racial, esse acaba sempre sendo o ponto de tensão na realidade atual: a qualidade e a intensidade do investimento necessário para perceber avanços.

Numa sociedade racialmente organizada em detrimento dos segmentos populacionais negros e indígenas, o advento de pandemias irá sempre expor o impedimento de grande parte destes em se prevenir, se cuidar e de resguardar a vida. Nesse contexto, não é possível promover desenvolvimento social desejado, sem realizar o devido enfrentamento ao racismo. (SANTOS, 2001; ALMEIDA Jr, 2012).

\section{Sobre as condições objetivas para o enfrentamento a COVID-19 numa sociedade racista e desigual}

A síntese de indicadores sociais do IBGE publicada em 2019 informou que em 2018 a extrema pobreza atingiu 13,5 milhões de pessoas:

A pobreza atinge sobretudo a população preta ou parda, que representa $72,7 \%$ dos pobres, em números absolutos 38,1 milhões de pessoas. E as mulheres pretas ou pardas compõem o maior contingente, 27,2 milhões de pessoas abaixo da linha da pobreza.

Em 2018, a redução da pobreza se deu principalmente no Sudeste, que registrou menos 714 mil pessoas nessa condição, sobretudo no estado de São Paulo (menos 623 mil). Quase metade (47\%) dos brasileiros abaixo da linha de pobreza em 2018 estava na região Nordeste. O Maranhão foi o estado com maior percentual de pessoas com rendimento abaixo da linha de pobreza, $(53,0 \%)$. Já Santa Catarina, que também se mostrou o estado menos desigual, apresentou o menor percentual de pobres. Todos os estados das regiões Norte e Nordeste apresentaram indicadores de pobreza acima da média nacional. (IBGE, 2020)

Quanto às condições de moradia e saneamento básico, os dados são os seguintes:

Em relação às condições de moradia, $56,2 \%$ (29,5 milhões) da população abaixo da linha da pobreza não têm acesso a esgotamento sanitário; $25,8 \%$ (13,5 milhões) não são atendidos com abastecimento de água por rede; e 21,1\% (11,1 milhões) não têm coleta de lixo.

Tanto em relação às inadequações habitacionais como em relação à ausência de saneamento, as proporções registradas são maiores entre pretos e pardos do que entre brancos. Entre pretos e pardos, 42,8\% (49,7 milhões) não são atendidos com coleta de esgoto; $17,9 \%$ (20,7 milhões), não têm abastecimento de água por rede; e 12,5\% (14,5 milhões) não têm acesso a coleta de lixo. (lbidem)

Dadas essas condições, é notório que para milhões de pessoas no Brasil que sobrevivem no subemprego e vivem com menos de $R \$ 145,00$, garantir boa alimentação, boas condições de higiene, saúde e isolamento social se trata de uma tarefa muito difícil. Não à toa, os auxílios emergenciais aparecem como medidas que contam com o apoio dos diversos setores políticos da esquerda à direita.

No âmbito do governo federal, o auxílio emergencial de $R \$ 600,00$ está sendo disponibilizado por 3 meses; no estado da Bahia, foram diversas as iniciativas de auxílio, tais como isenção de contas de água, energia 
elétrica, distribuição de cestas básicas e auxílio alimentação para estudantes da rede estadual, ações para apoio a população em situação de rua; no município de Salvador, com recursos da rede SUAS, também foram disponibilizadas cestas básicas, abertura de centenas de novas vagas emergenciais em unidades de acolhimento, além da complementação e estruturação do Consultório na Rua funcionava com equipes insuficientes e incompletas.

A população empobrecida acostumada a batalhar para sobreviver vai se organizando com esses recursos na medida em que consegue acessá-los, em alguns casos, com dificuldade, pela exigência de algum grau de inclusão digital (que não há), falta de documentos e pela redução dos serviços da Rede SUAS $^{3}$ nos bairros, com a reorganização do fluxo da rede municipal no contexto da COVID-19.

O amanhã, que vem sendo chamado por alguns de "sociedade pós-COVID", pode não guardar boas novidades para essas pessoas que seguem a luta diária por sobrevivência. Muitos têm certeza de que não sairemos iguais, ocorre que sair melhores não é uma consequência natural, para isso terá que haver intencionalidade política.

A atmosfera de solidariedade e colaboração observada é fato, esta geração nunca testemunhou esse nível de mobilização de todos os setores da sociedade; porém, dadas as circunstâncias, não surpreende. O Brasil tem um povo solidário do ponto de vista de prestar auxílio em situações de emergência, os pontos de coleta cotidianas de alimentos por pessoas em situação de rua nas grandes capitais, assim como em Salvador$\mathrm{Ba}$, por exemplo, dão-se em grande medida por iniciativas de grupos voluntários e/ou religiosos. Essa atitude solidária é conhecida e esperada, o que está à prova é a capacidade de mobilização da sociedade quanto a um projeto político que, de fato, altere estruturalmente as condições de vida das pessoas e que reserve o assistencialismo para situações de catástrofe. Melhor ainda, um projeto de sociedade em que a tragédia social não seja o nosso normal.

Milton Santos disse que "a classe média não quer direitos, ela quer privilégio, custe os direitos de quem custar"(SANTOS, 1996/1997, p.133-134). Para além das doações pontuais, a sociedade precisa batalhar por direitos, por justiça social e abandonar o moralismo e o punitivismo que se apresenta às pessoas negras e empobrecidas para apressadamente vigiar, julgar e punir.

É neste sentido que me pergunto se a classe média é formada de cidadãos. Eu digo que não. Em todo caso, no Brasil não o é, porque não é preocupada com os direitos, mas com privilégios. O processo de desnaturação da democracia amplia a prerrogativa da classe média, ao preço de impedir a difusão de direitos fundamentais para a totalidade da população. $\mathrm{E}$ o fato de que a classe média goze de privilégios, não de direitos, que impede aos outros brasileiros ter direitos. E é por isso que no Brasil quase não há cidadãos. Há os que não querem ser cidadãos, que são as classes médias, e há os que não podem ser cidadãos, que são todos os demais, a começar pelos negros que não são cidadãos. (Ibid., p.133-134)

Nessas bases, o fenômeno do racismo não permitirá que o país de maioria negra rompa o impasse e conclua o seu processo de desenvolvimento socioeconômico por não criar disposição para correção de passivos históricos e por desumanizar e gerar sujeitos de "segunda categoria". Trata-se de relações de poder entre perspectivas civilizatórias que não construirá, por conceito, caminhos de simples consenso e de cessão de espaço. O conflito vem sendo a tônica e os contornos ao impasse vão se dando no campo da política, não escapando de argumentações acríticas e despolitizadoras para tema tão central à dinâmica socieconômica do país.

\footnotetext{
${ }^{3}$ Sistema Único de Assistência Social
} 


\section{Pela transformação social, nem um passo atrás}

Se os municípios estão anunciando acolhimento universal para pessoas em situação de rua, algo que era distante até no discurso, que se cumpra; se os governos passam a discutir como nunca a renda mínima para as famílias e o quanto a precarização das relações de trabalho reduzem a resiliência das camadas mais empobrecidas, que se cumpra a garantia de direitos às trabalhadoras; se os profissionais de saúde e assistência social estão alçados à linha de frente, para dar o suporte às pessoas mais empobrecidas, que se fortaleça o SUS e a SUAS. Ao contrário disto, entretanto, extrapolando o contexto COVID-19, assiste-se no Brasil um desmonte daquilo que poderia dar base para o povo brasileiro se erguer: acesso a direitos e serviços básicos.

Sendo assim, aqueles que, no contexto COVID-19, organizam-se em coalizão pelo cuidado às pessoas menos favorecidas, devem organizar as suas pautas políticas em favor de uma transformação social que não submeta os princípios de dignidade humana ao racismo trasvestido de burocracia. Se o outro é enxergado como ser humano, não deve haver burocracia que the negue a dignidade. $O$ princípio do direito das mulheres, homens, crianças, travestis e transexuais... não deve sucumbir ao racismo do burocrata.

Tudo isso posto, não é bom que voltemos ao "normal" na suposta sociedade pós-COVID-19", o normal que estamos habituadas é uma tragédia social para milhões de pessoas silenciadas, o nosso normal não deve interessar a uma sociedade que queira de fato um mundo melhor.

\section{Referências}

ALMEIDA Jr., Ademário de Jesus. Administração e Racismo: ampliando as formas de análise do desenvolvimento sustentável. São Paulo: Hucitec, 2012.

CARNEIRO, Sueli. Movimento Negro no Brasil: Novos e velhos desafios. CADERNO CRH, Salvador, n. 36, p. 209-215, jan./jun. 2002

DEFENSORIA PÚBLICA DO ESTADO DA BAHIA. Relatório das audiências de custódias na comarca de Salvador/BA: anos de 2015-2018. / Defensoria Pública do Estado da Bahia. 1a. ed. - Salvador: ESDEP, 2019. $108 \mathrm{p}$.

IBGE, Síntese de indicadores sociais. Extrema pobreza atinge 13,5 milhões de pessoas e chega ao maior nível em 7 anos. Disponível em: <https://agenciadenoticias.ibge.gov.br/agencia-noticias/2012agencia-de-noticias/noticias/25882-extrema-pobreza-atinge-13-5-milhoes-de-pessoas-e-chega-ao-maiornivel-em-7-anos >. Aacesso em 24 abr. 2020.

IBGE. Síntese de indicadores sociais : uma análise das condições de vida da população brasileira : 2019. IBGE, Rio de Janeiro, 2019. Disponível em: <https://biblioteca.ibge.gov.br/index.php/bibliotecacatalogo?view=detalhes\&id=2101678> ; acesso em 24 - 4 -2020.

MOORE, Carlos. Racismo e Sociedade: novas bases epistemológicas para entender o racismo. Belo Horizonte: Mazza edições, 2007.

MUNANGA, Kabenguele. Rediscutindo a mestiçagem no Brasil: identidade nacional versus identidade negra. Belo Horizonte: Autêntica, 2004.

SANTOS, Milton. As cidadanias mutiladas. O preconceito (vários autores). São Paulo: IMESP, 1996/1997. P.133-134

SANTOS, Hélio. A Busca de um Caminho Para o Brasil: a Trilha do Círculo Vicioso - Hélio Santos. Editora Senac: 2001 